\title{
Investigation and Analysis of Vocational Training and Professional Identity of Biology Teachers in Southern Henan
}

\author{
Bo Peng ${ }^{1}$ Xiaojie Xu${ }^{1}$, Nongyi Zheng ${ }^{1}$, Feng Peng ${ }^{2}$, Xuezhong Sun ${ }^{3}$, Xiayu Tian ${ }^{1}$, Lulu He ${ }^{1}$, Zhuanqing Yang ${ }^{1}$, \\ Yanfang Sun ${ }^{1}$, Ruihua Pang ${ }^{1}$, Jintao Li ${ }^{1}$, Quanxiu Wang ${ }^{1}$, Wei Zhou ${ }^{1}$ \& Hongyu Yuan ${ }^{1}$ \\ ${ }^{1}$ College of Life Sciences and Institute for Conservation and Utilization of Agro-bioresources in Dabie \\ Mountains, Xinyang Normal University, Xinyang, China \\ ${ }^{2}$ Biology Teaching Group, Gushi No. 1 Middle School, Gushi County, Henan, China \\ ${ }^{3}$ HeNan XinYang Senior High School, Xinyang, China \\ Correspondence: Bo Peng, College of Life Sciences and Institute for Conservation and Utilization of \\ Agro-bioresources in Dabie Mountains, Xinyang Normal University, Xinyang 464000, China. E-mail: \\ pengbo@xynu.edu.cn \\ Hong-Yu Yuan, College of Life Sciences and Institute for Conservation and Utilization of Agro-bioresources in \\ Dabie Mountains, Xinyang Normal University, Xinyang 464000, China. E-mail: yhongyu92@163.com
}

Received: September 28, 2019 Accepted: October 19, 2019 Online Published: October 23, 2019

doi:10.5539/jedp.v9n2p172

URL: http://doi.org/10.5539/jedp.v9n2p172

\begin{abstract}
In order to effectively investigate the current professional status of biology special post teachers in the southern of Henan Province (Southern Henan), this study used the method of interviews and questionnaires to investigate and analyze the current situation of biology special post teachers in Southern Henan from the aspects of vocational training and professional identity. The results showed that: (1) Satisfaction with vocational training is still acceptable, all of them can participate in certain training, but the training policy and system need to be improved, the level of training is limited, the training opportunities are not balanced, and the training time and content need to be optimized. (2) Career identity is generally satisfactory, proud, respected and enthusiastic in teaching. It can promote the growth and development of students, but the suggestions of special post teachers have not been adopted in time. In view of the above findings, this paper puts forward some countermeasures for the professional development of biology special post teachers in Southern Henan, in order to provide theoretical basis for the follow-up study on the professional aspects of biology special post teachers, and also provide important information for the professional development of rural special post teachers.
\end{abstract}

Keywords: Southern Henan, vocational training, career identity, biology, special post teachers, investigation and analysis

\section{Introduction}

In 2006, the Ministry of Education, the Ministry of Finance, the Ministry of Personnel and the Central Editorial Office jointly issued the notice of the special job plan for school teachers at the stage of compulsory education in rural areas, hereinafter referred to as the "Special Job Teacher Plan". The aim of the plan is to innovate the mechanism of rural teachers' supplement, strengthen the effective supplement of rural teachers (Hu, 2010), solve the problems of insufficient total teachers and unreasonable structure in rural areas (You, Yang, \& Zhang, 2017), and continuously improve the quality of rural school education. Since the implementation of the "special post teacher plan" in 2009, Henan Province has attracted a large number of outstanding university graduates, especially the undergraduate graduates of normal education major, to join the special post teacher industry (Yang, 2017; Feng \& Yan, 2018). This has effectively promoted the employment of college students in Henan Province, improved the quality of basic education in rural areas, and played an important role in promoting the balanced development of compulsory education in Henan Province. From the beginning of the implementation of the "special post teacher plan" in Henan Province to September 2012, a total of 300,000 special post teachers (Tian et al., 2013) were recruited in Henan Province. So far, the total number of special post teachers recruited in Henan Province has exceeded 100,000, and the number of special post teachers recruited in Henan Province in 2017 alone reached 15,300 (Feng et al., 2018). These special post teachers have injected fresh blood into rural 
schools and brought strong aftereffect for the sustainable and healthy development of rural education.

In 2019, the Special Post Teachers Program has been successfully implemented in Southern Henan for ten years. It has played an important role in gradually solving the problems of insufficient teachers and unreasonable structure of teachers in rural schools of Southern Henan, improving the overall quality of teachers in rural areas of Southern Henan, and effectively promoting the balanced development of urban and rural educational resources. However, at the same time, the co-existence and development of special post teachers, on-the-job teachers and new special post teachers have emerged. Many special post teachers are more entangled on the issue of whether to stay or not after their expiration, and various contradictions about special post teachers are constantly highlighted (Zhang, 2016; Wang \& Liu, 2013). The overall level of economic and social development in Southern Henan is relatively low, and the rural education hardware facilities are still relatively backward. At the same time, the population base in Southern Henan is relatively large, especially the huge agricultural population, which will lead to a considerable difficulty in the implementation of relevant education policies, and its education is also more difficult. The overall enrollment rate of students in Southern Henan is relatively low, and the overall quality of education and teaching is not optimistic (Tian \& Wang, 2013). Therefore, many excellent biology graduates are reluctant to teach in Southern Henan.

How about the vocational training and professional identity of the special post teachers of biology in the south of Henan Province? What difficulties they have in the process of their professional development? All sectors of the society pay close attention to such problems. Therefore, in order to effectively investigate these situations, three representative counties (Gushi County, Luoshan county and Tanghe County) were selected in the south of Henan Province to investigate and analyze the professional status of special post teachers of biology in the south of Henan Province from the aspects of professional identity and vocational training. This study mainly uses the method of questionnaire to collect data. In this study, 120 questionnaires were distributed. After careful examination, 8 questionnaires with incomplete answers were deleted and 112 valid samples were collected. With the help of individual interview method, 15 interviewees were drawn up through the design of relevant interview outlines to obtain the information related to this study. After taking back the questionnaire and coding the questionnaire, we use mathematical analysis method to make statistical analysis of the collected data, in order to provide reference and reference for the sustainable development of special post teachers in Southern Henan.

\section{Professional Training of Biology Special Teachers in Southern Henan}

At present, the basic education reform in our country is aiming at realizing the development of primary and secondary school curriculum from subject-based and knowledge-based to paying attention to every student. There are obvious innovations and breakthroughs in curriculum structure, function and content with the original curriculum, which brings severe challenges to teachers of basic education. Therefore, special post teachers must timely update educational and teaching concepts, upgrade educational and teaching methods, optimize educational and teaching behavior, enrich educational and teaching means, broaden knowledge system, improve knowledge structure and constantly improve the level of professional knowledge through vocational training. Only in this way can we make a positive contribution to basic education under the relatively difficult conditions in the south of Henan Province.

\subsection{Institutions and Ways of Pre-service Training for Biology Teachers}

At present, although newly recruited teachers in Southern Henan have solid professional knowledge, they do not graduate from normal universities, so to some extent, they still lack the basic education knowledge and basic skills necessary for teachers' teaching. Therefore, pre-service training is one of the important ways for special post teachers to acquire educational expertise. The effect of pre-service training has a direct impact on the overall level of education in Southern Henan. Through the analysis of the survey results, it is found that the pre-service training institutions for special post teachers are: Normal universities accounted for $62.5 \%$, training institutions $31.2 \%$ and normal colleges $6.3 \%$. This is basically consistent with the proportion of teachers' majors in the professional structure. In addition, $87.5 \%$ of the biology specialist teachers indicated that other institutions were needed to provide effective assistance for their pre-service training. Therefore, we should not neglect the experience and opportunities of theoretical study or internship provided by training institutions for special-duty teachers before they take up their posts. Through the investigation of the ways of pre-service training for special posts teachers in biology, we can find that curriculum learning and practical experience are indispensable in pre-service training for special posts teachers in biology. However, there are obvious differences in the proportion of curriculum learning and practical experience. In the process of pre-service training for special post teachers of biology, the study of courses is the main part, and the practice is the supplement. According to the survey results, statistics show that: $81.2 \%$ of special post teachers in biology had only $1-2$ off-campus internships 
or internships, $12.5 \%$ of special post teachers in biology had no off-campus internships at all, $17.8 \%$ of them had no off-campus internships, and a considerable number of special post teachers had pre-service training through other means (Figure 1). Thus, in the pre-service training of special post teachers of biology, the development of curriculum learning and practical experience is not balanced, and most of them lack the accumulation of practical experience.

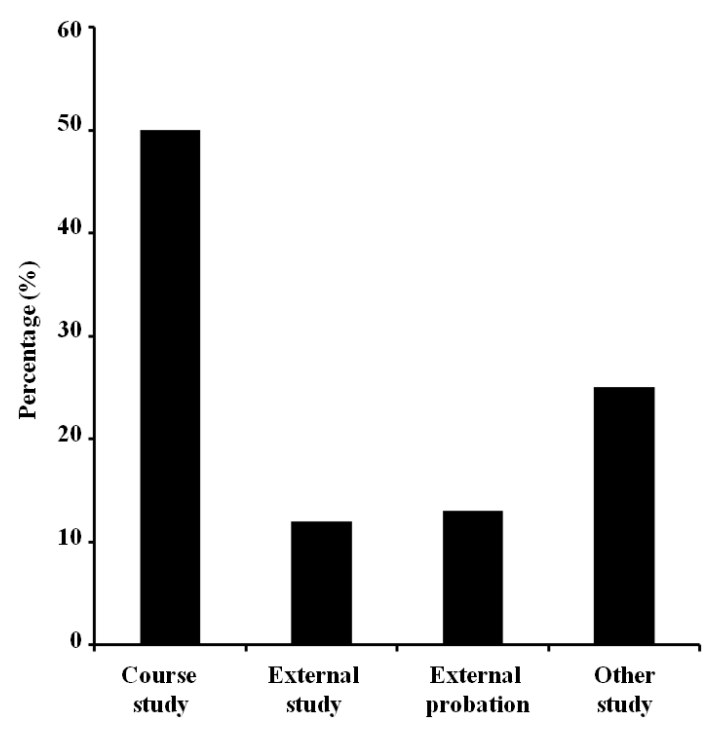

Figure 1. Main approaches to pre-service training

\subsection{Policy and System of Teacher Training in Biology Specialty Post}

In the early stage, special post teachers mainly cultivate their basic abilities and actively adapt to the reform of education and teaching. In the early stage, special post teachers mainly train teachers' basic abilities, actively adapt themselves to the reform of education and teaching, and strengthen the informationization construction of teacher education. However, with the rapid development of education and teaching reform, the current teacher training policy is inclined to rural areas, and further strengthen the construction of teachers' morality, cultivate and cultivate a group of high-quality teachers. Special post teacher training policy is an important basis to guide the development of special post teacher training in biology. It links the development of special post teacher training theory with the practice of special post teacher training. Through investigation and analysis, it is found that: $12.5 \%$ of the special post teachers of biology said that the school did not have policies, systems and regulations for the further education and training of special post teachers, $43.7 \%$ of the special post teachers of biology said that the school had relevant policies, but there were some restrictions on the training of special post teachers; Only $43.8 \%$ of the teachers thought that the relevant policies, systems and regulations of the school were very good. Therefore, the formulation of training policy and system for biology specialist teachers in Southern Henan needs to be further improved, and the external environment needs to be improved in order to provide more training resources.

\subsection{Levels and Opportunities of Advanced Education Training for Biology Teachers}

Special post teachers are mostly new teachers, and a certain proportion of non-normal graduates, their professional knowledge reserve and application ability can not fully meet the needs of primary and secondary education and teaching. Especially, teachers graduated from non-normal colleges still lack knowledge in education and psychology. Therefore, it is particularly important to train special-duty teachers and improve their skills in education and teaching. According to the analysis of survey results, most of the schools taught by biology teachers are located in counties or townships, and the leading organizations of their further training are in turn: County education departments $(42.9 \%)$, general schools $(35.7 \%)$, municipal further education schools $(7.1 \%)$ and research rooms (14.3\%) (Figure 2). From the survey results, it can be found that the training of biology special post teachers in Southern Henan has been limited to a certain extent due to the geographical influence. 


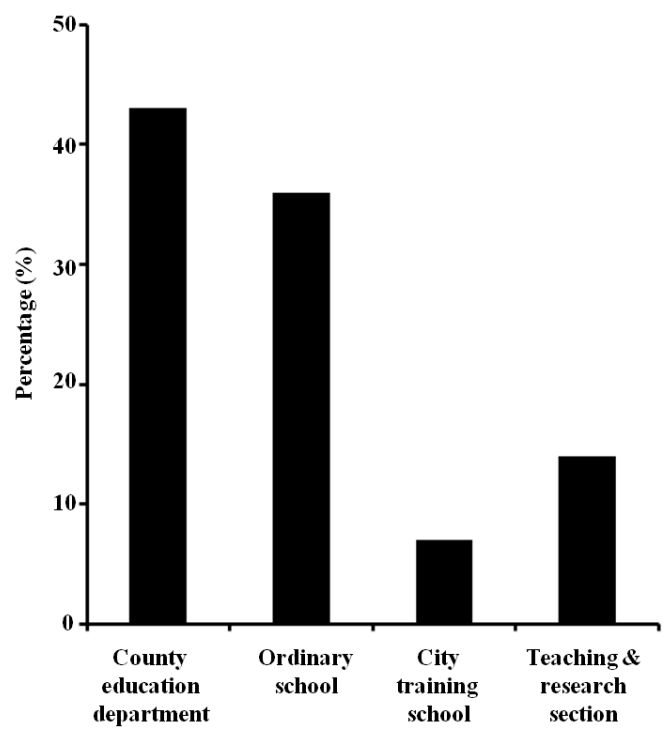

Figure 2. Leading organization of refresher training

In addition to the influence of the region, the further training of biology special post teachers in Southern Henan is restricted by many other factors. As a result, there are few opportunities for further training of biology special post teachers. According to the survey, $68.7 \%$ of the teachers only had 1-2 training sessions after entering the post, and $43.8 \%$ of the teachers said that they had fewer opportunities for further training after entering the post. At the same time, whether or not to participate in further education training is affected not only by the region, but also by the title $(35.0 \%)$, teaching age $(22.5 \%)$, performance appraisal $(17.5 \%)$, establishment $(15.0 \%)$, educational background (5.0\%) and salary (5.0\%) (Figure 3). Whether special post teachers can participate in further training is affected by many factors, and the opportunities are not balanced. Especially the newly recruited biology special post teachers, because of the influence of their professional title and teaching age, can't get the same training opportunities as the old teachers, which is very harmful to the development of new special post teachers.

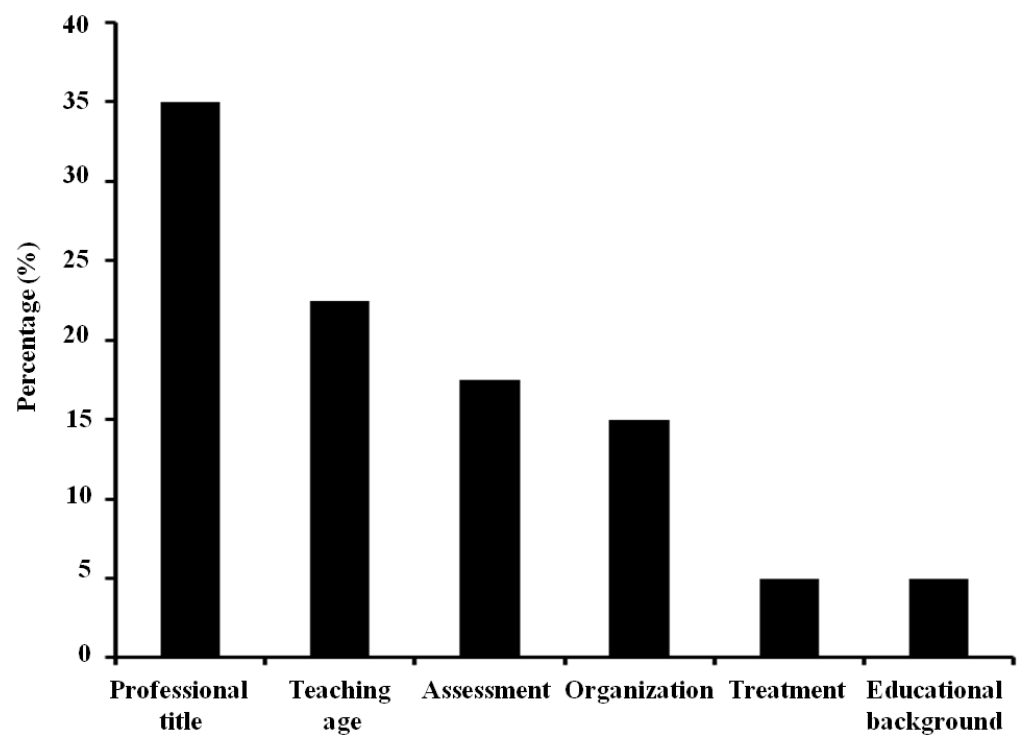

Figure 3. Influencing factors of in-service refresher training 


\subsection{Time and Content of Biology Teachers' Participation in Further Education Training}

Reasonable arrangement of the time and content of special post teachers' further training will inevitably improve the quality and effectiveness of special post teachers' further training. It is helpful to improve the satisfaction degree of special post teachers to further training, and then to achieve the purpose and effect of further training. After comprehensive analysis of interviews and questionnaires, it was found that $50.0 \%$ of biology special post teachers took part in refresher training during normal teaching hours in schools, and $31.2 \%$ of biology special post teachers said that they mainly took part in training during winter and summer vacation. Therefore, only $12.5 \%$ of the biology special post teachers were satisfied with the schedule of further training, and $62.5 \%$ of the biology special post teachers were basically satisfied with the schedule of training. It can be seen that the satisfaction of biology teachers with the current training schedule is general.

In terms of training content, it is necessary to focus on the lack of experience and skills in education and teaching of special post teachers, especially newly graduated special post teachers. We should strengthen training on how to deal with the relationship between teachers and students, how to improve the methods and skills of education and teaching, and how to do a good job in the specific methods of education and teaching. The content of training should be in line with the actual work of education and teaching, and has practical significance and role. As far as possible, we should avoid the single form of training and the lack of effectiveness and pertinence in content. According to the survey, $81.3 \%$ of the Specially-Appointed biology teachers expressed satisfaction or basic satisfaction with the training content. It is worth noting that the teachers in the specialty post of biology thought that they need training in teaching skills $(75.0 \%)$, subject expertise $(68.8 \%)$, teaching theory $(62.5 \%)$, teaching reflection $(37.5 \%)$ and teaching research $(31.3 \%)$.

\subsection{Satisfaction with the Training Effect of Biology Teachers}

Whether the policy, system, level, opportunity, time and content of special post teachers' further training are appropriate or not can be reflected to a certain extent through the satisfaction of the final training. Through interviews and questionnaires, it can be found that $87.5 \%$ of the biology special post teachers thought that further training is very helpful or helpful to improve their educational and teaching abilities, $6.2 \%$ of the special post teachers of biology thought that further training is not helpful to the improvement of their educational and teaching abilities. $75.0 \%$ of the special post teachers of biology expressed great satisfaction or satisfaction with the final effect of the training, which indicated that the teachers of biology in Southern Henan were generally satisfied with the training.

\section{Professional Identity of Biology Special Post Teachers in Southern Henan}

Teacher's professional identity is a comprehensive reflection of teachers' understanding of their own role, professional pride and degree of respect. Good professional identity is one of the internal driving forces of teachers' self-growth, as well as the psychological foundation for teachers' career, which will directly affect their work performance. At the same time, good professional identity plays a role in promoting the professional development of teachers, and it is also an important basis for stabilizing teachers and improving their overall quality (Li, Song, \& Wang, 2011). Special post teachers have just entered vocational teaching for a short time. Their professional identity not only relates to their own career development, but also affects the quality of local education (Xu \& Song, 2012). Therefore, it is very important to investigate the professional identity of biology special post teachers in Southern Henan.

\subsection{Professional Pride of Biology Special Post Teachers}

By investigating and analyzing the pride of the biology teachers in the south of Henan province, it was found that $56.2 \%$ of the teachers were proud of themselves as a biology teacher, and $25.0 \%$ of the teachers were very proud of being a biology teacher; only $18.8 \%$ of the teachers felt no proud in being a biology teacher. Among them, $68.8 \%$ of the biology specialty teachers said that they were willing to mention that they were specialty teachers when introducing themselves, and they basically agreed with their gratification; $25.0 \%$ of biology special post teachers said that they were very happy to introduce themselves as a special post teacher, and they very agreed with the gratification; only $6.2 \%$ of biology special post teachers were unwilling to mention themselves as a biological special post teacher when introducing themselves, and they did not agree with the gratification (Figure 4). Therefore, $81.2 \%$ of the special post teachers of biology in Southern Henan have a sense of pride, and $93.8 \%$ of the teachers are willing to explain themselves as a special post teacher when introducing themselves, which shows that most of the special post teachers of biology have a strong sense of pride. 


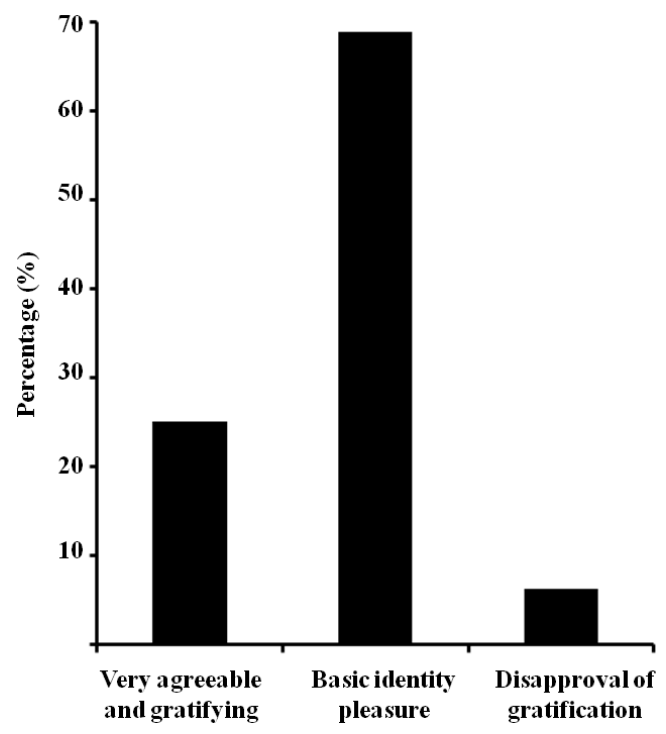

Figure 4. The gratification of the special post teachers

\subsection{The Growth and Development of Students Promoted by Biology Special Post Teachers}

By means of interview and questionnaire, this paper made an investigation and analysis on the promotion of students' growth and development by biology special post teachers in Southern Henan, and the results showed that: $62.5 \%$ of the Specially-Appointed biology teachers basically agreed that teachers' work played an important role in promoting students' growth and development; $37.5 \%$ of the teachers highly agreed that the biology special post teachers could promote the growth and development of students. Up to $87.5 \%$ of the biology special post teachers expressed their gratification or very gratification when they saw or heard the words praising the special post teachers, while only $12.5 \%$ of the biology special post teachers expressed their general gratification.

\subsection{The Teaching Enthusiasm of the Biology Special Post Teachers}

Teachers' enthusiasm for teaching plays a decisive role in improving students' academic performance and overall quality. Teachers who devote themselves to teaching with full enthusiasm can continuously improve their teaching ability, renew their teaching ideas and improve their professional quality. In order to investigate whether the biology special post teachers in Southern Henan devote themselves to teaching with full enthusiasm, the teaching enthusiasm of the special post teachers in Southern Henan was analyzed by means of interviews and questionnaires. The survey results showed that $81.2 \%$ of the special post teachers of biology indicated that they could basically devote themselves to their teaching work with full enthusiasm; another $18.8 \%$ of the special post teachers of biology said that they could not meet this requirement. In addition, the survey results showed that $75.0 \%$ of teachers could improve their teaching methods and means actively and continuously improve the quality of education and teaching. Therefore, more than $80 \%$ of biology special post teachers in Southern Henan can devote themselves to education and teaching with full enthusiasm, which will play an important role in improving the overall quality of education in Southern Henan.

\subsection{The Degree of Respect for Biology Special Post Teachers}

At present, the most fundamental competition between countries is the competition of excellent talents, and the cultivation of excellent talents requires excellent teachers. Respecting teachers and valuing education is a fundamental, forward-looking and strategic investment in a country's future. The more respected teachers are, the more future the country will have. According to the survey, $68.8 \%$ of the biology special teachers said they could feel the respect of their colleagues in their work, and $31.2 \%$ of the teachers said that they are highly respected by their colleagues at work. $81.3 \%$ of the teachers said that they could feel the respect of students' parents or others in their work; while $18.7 \%$ of the teachers said that they were highly respected by students' parents or others at work. Therefore, no matter colleagues, parents or others, they can fully transform respecting teachers and loving teachers into action consciousness, so that the biology special post teachers in South Henan can feel respected. 


\subsection{The Adoption of the Suggestions of the Biology Special Post Teachers}

Special post teachers often live in remote rural areas, compared with urban schools, the working and living environment of special post teachers is relatively backward. This kind of teaching and living environment is the unique feature of the special post plan, which has created the particularity of the teaching work of the special post teachers. Then, special post teachers will encounter some problems in their daily teaching and life, and may make suggestions to schools. In order to investigate the adoption of the suggestions of the biology special post teachers in Southern Henan, interviews and questionnaires were conducted. The results showed that: when asked whether the school leaders could listen to and implement the suggestions of the special post teachers, $62.5 \%$ of the biology teachers said that the school leaders could basically listen to and implement the suggestions of the grassroots teachers, while $12.5 \%$ of biology special post teachers highly agreed with this view (Figure 5). Interestingly, $18.8 \%$ of the special post teachers of biology indicated that the school leaders could not listen to and implement the suggestions of the grass-roots teacher well, and $6.2 \%$ of the special post teachers of biology indicated that the school leaders failed to listen to and implement the suggestions of the grass-roots teachers.

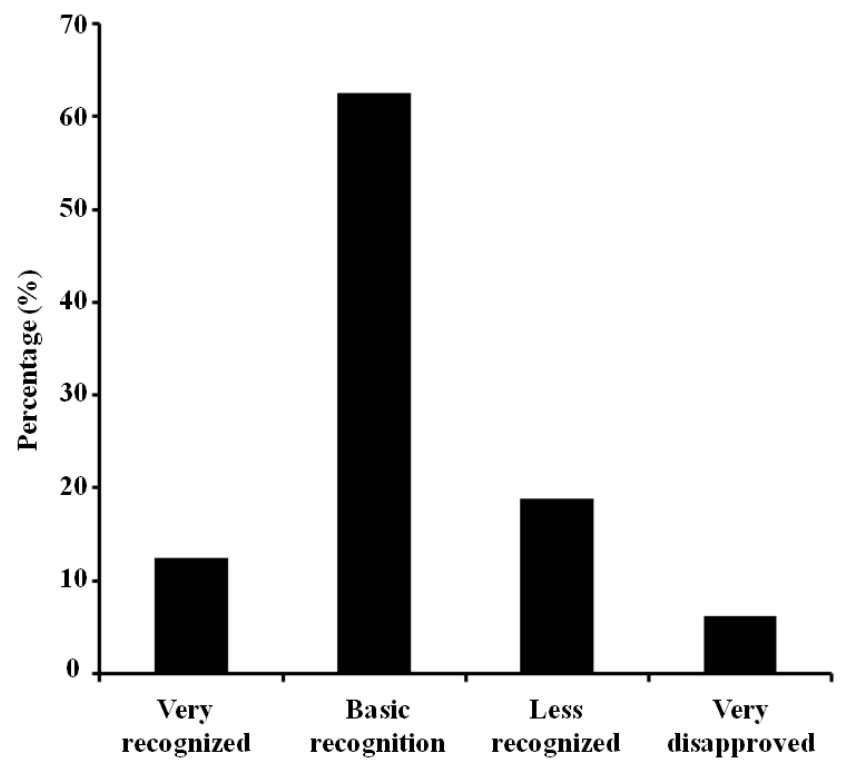

Figure 5. Acceptance of teachers' recommendations by school leaders

\section{Professional Development Strategy of Biology Special Post Teachers in Southern Henan}

\subsection{Promote the Professional Development of Biology Special Post Teachers}

In terms of the policy of the "special post teacher plan", the state has only made overall deployment and arrangement at the macro level. It is the duty of local governments at all levels to flexibly formulate relevant rules for special post teachers in light of the actual situation of each region. In particular, the pre-employment and post-employment training and professional development of most teachers in special posts are basically solved by local finance, which requires the local government to increase education investment in poor, remote and backward rural areas from the perspective of the overall situation of education. Teachers in special posts of biology go to the countryside, because they have fewer opportunities for further training, they basically have no chance to participate in training and continuing education, and can only rely on self-study. However, teachers in special posts have a large number of teaching classes, and the time they can use to improve their ability and level of personal professional knowledge is not much, which seriously limits their ability and level of professional knowledge.

Special post teachers are in the induction period, most of them take part in work not long ago, which is the most critical period in the whole career. Paying more attention to the professional development of special post teachers is not only the need to solve practical problems, but also the need to build a long-term stable and quality rural teachers team (Tian et al., 2013). In addition, the issue of whether to stay or not after the expiration of the special post teachers' tenure is also a hot topic of current social concern (Wang \& Cao, 2019). Cities have abundant social resources and vast space for professional development, which is the main driving force for biology 
teachers to choose from rural to urban areas. Therefore, in order to avoid short-sighted behavior and establish a long-term and stable management mechanism, the relevant departments should improve the relevant policies of the "special post plan" (Yang, 2019). At the same time, it is necessary to further improve the school's various management systems and take targeted measures. Special post teachers themselves also need to change their induction concepts and make joint efforts to ensure that the teachers of biology special post can teach with peace of mind and enthusiasm.

\subsection{Develop High-Quality Vocational Training}

Among the special post teachers, there are a certain number of graduates from non-normal universities. Their professional quality, professional knowledge reserve and application ability can not meet the needs of education and teaching very well. Especially the special post teachers graduated from non-normal universities have not received systematic knowledge of pedagogy and psychology. Therefore, it is necessary to strengthen the relevant vocational training of special post teachers before and after their employment, so as to improve their educational and teaching ability and level. In the investigation of the training of special post teachers in biology, it was found that most of them graduated from normal universities, but $87.5 \%$ of special post teachers in biology still need the assistance of other institutions to complete pre-service training, which indicates that the pre-service training of schools needs to be improved. The purpose of pre-service training is to stimulate the professional passion, set up professional ideal and cultivate team consciousness of newly-recruited special post teachers, help them to define their growth goals, plan their career, grasp the basic routine operation process of education and teaching as soon as possible, and successfully complete the role transformation from students to teachers (Yuan, 2018). At the same time, normal colleges should also strengthen the training of students' practical ability. While helping students complete the course, they should create more opportunities for practice and internship, and promote the accumulation of students' practical experience. When formulating training policies, the educational administrative departments and schools should consider the professional basis of the special post teachers themselves, take into account the effective connection between pre-service and post-service, and carry out training with emphasis (Luo et al., 2019). In carrying out the training of special post teachers, we should prevent the tendency of "urbanization", "frontier" and "irrelevance" of training courses (Feng, 2015). Educational administrative departments should strengthen training efforts, actively innovate training mechanisms, reduce constraints on special post teachers' participation in training, increase opportunities for further training, so that all teachers have equal opportunities for further training, and constantly promote the renewal of educational and teaching ideas and the continuous improvement of teaching quality.

Among the open questions in this questionnaire, many special post teachers put forward some valuable suggestions on the content and time of training. For example, training time should be arranged as far as possible on weekends or in winter and summer holidays; the training content should conform to the current situation of rural education and teaching; the training methods should be diversified; and the training of multimedia application should be increased. It can be seen that scientific and reasonable arrangement of the time and content of the further training will improve the satisfaction of biology special post teachers in the further training, and also have a positive impact on teachers' education and teaching.

\subsection{Improve the Salary and Welfare of Biology Special Post Teachers}

Only by improving the basic living security of special post teachers and letting them have no worries, can they be reassured, enthusiastic and lifelong in teaching. Regrettably, according to the results of salary satisfaction survey, $66.7 \%$ of the Specially-Appointed teachers of biology expressed dissatisfaction or very dissatisfaction with the salary level. Imperfect infrastructure, lack of material conditions and low salary are still the main reasons that hinder the retention of rural special post teachers (Tang \& Wang, 2019). Special post teachers have made great contributions to improving the current situation of education and teaching in poverty-stricken areas, but their economic status has not been improved accordingly. Life worries will inevitably have a negative impact on the working status of special post teachers. Therefore, the relevant departments should improve the local allowances and social security benefits for special post teachers, and formulate and implement the basic standards of work and life security for special post teachers. At the same time, it is necessary to make clear provisions on the safety, transportation, accommodation and working environment of special post teachers, so as to ensure the basic conditions of their work and life, and to stimulate their enthusiasm for work.

Most of the schools taught by special posts teachers are located in remote counties or towns. Many special posts teachers live alone away from their families, and often feel lonely. Therefore, special post teachers will inevitably have various psychological problems, which need to be paid enough attention by relevant departments (Liang, 2019). The whole society should pay more attention to the special post teachers, deepen the humanistic 
care, and strengthen the communication and exchange between them (Tian et al., 2013). It is suggested that the administrative department of education at the county level should take the lead to set up regional research and friendship teaching organizations in rural poverty-stricken areas with scattered special post teachers as the main body and similar township schools as units to create a good communication environment. It can not only exchange learning experience with each other, promote the improvement of professional level, but also enhance the communication between special post teachers in life and emotions, create favorable conditions for young special post teachers to make love and friends, and lay a solid foundation for them to take root in the countryside and serve rural education.

\section{Acknowledgements}

This work was financially supported by Postgraduate Education Reform Project of Henan Province (2019SJGLX088Y), The Training Plan of Young Backbone Teachers in Colleges and universities of Henan Province (2019GGJS162), Special Research Project of Teacher Education Linkage Development Community in Southern Henan (2019-GTTYB-01), Research Project of Teacher Education Curriculum Revolution of XYNU (2019-JSJYYJ-10), Nanhu Scholars Program for Young Scholars of XYNU (2016054) and Postgraduate Research Innovation Project of XYNU (2018KYJJ47).

\section{References}

Feng, J., \& Yan, Y. (2018). Investigation and research on the present situation of the work and life of special-post teachers in Henan Province. Talents Training and Employment, 11, 48-53.

Feng, L. X. (2015). Investigation and research on the training needs of "special post teachers" in rural schools-taking junior middle school mathematics teachers in Shanxi Province as an example. Educational Theory and Practice, 35(20), 34-36. https://doi.org/1004-633X(2015) 20-0034-03

Li, L. Z., Song, Y. Y., \& Wang, L. (2011). Survey on the current situation of teacher professional identity of free normal students. Contemporary Teacher Education, 4(2), 53-58. https://doi.org/ 10.16222/j.cnki.cte.2011.02.014

Liang, L. Y. (2019). Research on the present situation of professional life of special post teachers. Guangxi Normal University.

Luo, X., Wang. X. H., Chang, L. J., \& Zhang, J. K. (2019). Rural primary school teachers group work status survey and research. Rural Education in China, 9, 79-79+127.

Tang, Y. P., \& Wang, H. (2019). Why to retain rural teachers: an empirical study based on the research data of special post teachers in G Province. Education Research, 40 (4), 134-143.

Tian, B. J., \& Wang, Y. (2013). Investigation and reflection on the current situation of the implementation of the "special post teacher plan"-based on the case study of T County in Henan Province. Journal of Inner Mongolia Normal University (Educational Science Edition), 26(10), 60-62. https://doi.org/1671-0916(2013)10-0060-03

Wang A. Q., \& Liu, F. (2013). Problems and solutions in the professional development of special-post teachers. Educational Theory and Practice, 31, 37-40. https://doi.org/1004-633X (2013)31-0037-04

Wang, J., \& Cao, N. X. (2019). A narrative study on the dilemma of a special post teacher in rural areas. Educational Guidance Journal, 8, 44-48. https://doi.org/10.16215/j.cnki.cn44-1371/ g4.2019.08.009

$\mathrm{Wu}, \mathrm{Y}$. (2010). Analysis of educational policy: taking teachers' special post program in rural schools as an example. Educational Theory and Practice, 30(1), 28-30. https://doi.org/1004- 633X(2010)01-0028-03

Xu, J. C., \& Song, Z. (2012). Investigation and Study on the development status of rural special post teachers. Contemporary Education and Culture, 4(1), 58-64. https://doi.org/ 10.13749/j.cnki.cn62-1202/g4.2012.01.010

Yang, F. (2017). Research on teachers' second career choice intention of tegang: a survey from Xinxian County, Henan Province. Hunan Normal University.

Yang, S. X. (2019). Research on the problems and solutions of special post teachers. Times of Think Tank, 31, 195-196. https://doi.org/2096-4609(2019)31-0195-002

You, Y., Yang, J., \& Zhang, Y. (2017). An analysis of the effectiveness of teachers'policy in special post: a perspective of teachers' team and education equity. Fudan Education Forum, 15(5), 83-90. https://doi.org/10.13397/j.cnki.fef.2017.05.014 
Yuan, J. P. (2018). Effective strategies for pre-job training of new and special teachers. Journal of Ningxia University (Humanities and Social Science Edition), 40(6), 186-189. https://doi.org/1001-5744 (2018)06-0186-04

Zhang, A. H. (2016). Investigation on the present situation of special-post teachers in Hebei Province and research on development strategies-taking special-post teachers in rural Chinese as an example. Language Education, 4, 1-2. https://doi.org/10.16412/j.cnki.1001-8476.2016. 12.001

\section{Copyrights}

Copyright for this article is retained by the author(s), with first publication rights granted to the journal.

This is an open-access article distributed under the terms and conditions of the Creative Commons Attribution license (http://creativecommons.org/licenses/by/4.0/). 